\title{
Local Learnings: An Essay on Designing to Facilitate Effective Use of ICT s
}

\author{
Tony Salvador \\ Intel Corporation < tony.salvador@intel.com $>$ \\ John Sherry \\ Intel Corporation < john.sherry@intel.com >
}

\begin{abstract}
In this essay, we explore some of the details of what it takes to own, use and derive benefit from information and communication technologies, with a focus on regions where ICT adoption and use is especially low. We begin with a fairly meticulous description from our ethnographic work to which we'll refer throughout the paper. Though we consider this particular instance, we note that it represents of a wide range of instances from our ethnographic work in homes and businesses over several years in Brazil, Costa Rica, Chile, Ecuador, Bolivia, Peru, Korea \& India. Our goal in this paper, however, is to change the conversation from discussions of infrastructure and capacity building to considerations of local, lived conditions in actual homes and actual businesses to suggest design alternatives that make effective use of ICTs more amenable to various locales. We offer two design directions especially for high tech corporations: Designing for Locus of Control and Designing for Local Participation. Along the way, we'll argue to reframe of the current conception of "digital divide", putting the burden not on those with limited access, but on limited understanding within the high tech industry.
\end{abstract}




\section{Introduction}

We start with a fairly lengthy description Jose Miguel, his village and his use of computing. From this, and other examples of our ongoing ethnographic work, we offer two design directions which are subsequently discussed.

\section{Jose Miguel}

Walking down the road you can see the mud brick house, surrounded by a crumbly wall of adobe. The grounds of the small courtyard are uneven, reflecting years of erosion and compacting from rain and the walking of human and animals. A piece of PVC pipe pokes up out of the ground with a hand pump like those seen in some American western movies when people had to work to get water from the ground. Nearby is a large, plastic, blue barrel that is the water tank for the household. There's no hot water unless someone heats some. A dog lives in the courtyard and it is his job to guard the house. Other things are strewn about: a bicycle, the frame of a doghouse under construction, some drying clothes, and a variety of parts from a variety of devices.

To one side, a door of loose-fitting wooden slats opens onto a small room with a floor made of the same wooden slats. Just below the floor is dirt - dirt that sometimes works its way up from between the floorboards. There are no windows. The only light comes from the doorway when it's open. The ceiling is lined with newspaper to keep dust and debris from falling into the room when people walk on the floor above. Cloth coverings over clothes, books, and musical instruments serve as further defenses against the ubiquitous dust.

Back outside, along the perimeter of the courtyard, there are two tiny "chicken coops". Unlike Jose Miguel's room, both of the coops are heated. Yellow propane canisters sit right there on the ground with a hose running directly to a small heat lamp hung low over the floor to keeping the chicks warm. The floor of the coop is a comfortable tussle of wood chips and the chicks are fed nutritious food, which is more than the dog gets and sometimes more than the family gets.

Across the road, Jose Miguel works a small carefully tended organic garden with an American man who lives nearby with his wife, a photographer and Fulbright scholar. Jose Miguel is starting to apply his new college degree in "Agropecuario" (roughly animal husbandry and agriculture) to meet the needs of his home village. His chicken business is cleverly called "Pollitos Gigantes" (Giant Chicks). He's the first from his village of 83 households to graduate from college. His father, a poor farmer, was forced to sell some precious land to pay the college expenses of his second son, the only one of his five children to have this opportunity.

To finish his five-year program, Jose Miguel was required to research, write and orally defend what I can only report is the equivalent of an American master's thesis at any US college and a doctoral dissertation at some. With unbelievable good fortune, the American couple loaned him US \$200 (four to six month's income for many in the village) to "rent" a computer for four months from a computer vendor in a nearby city. (Although no such thing as "computer rental" is available in this part of the world, a private arrangement was made and secured by the Americans' cash loan.). Jose Miguel had four months to finish his thesis.

The computer and everything he needed was in that room. No windows, only light from the open door. Electricity - when there was electricity- was supplied through an extension cord run in from another room. A richly woven blanket covered the computer to keep away the gentle fallout of dust and dirt from the ceiling.

What's amazing to us is not that Jose Miguel had the computer in this poor room, but that he needed one. There were two other computers we knew of that were in use in the community. One was the result 
of a grant to the local civic organization; it sat in the director's office where it went mostly unused. The second wasn't actually in the community, but more than an hour's bus ride away where Jose Miguel and a few other people from his community were working in a homemade recording studio to make a CD of their music.

Other than that, there was no one else in his community who needed a computer enough to find a way to get one or get use of one. The village is mostly comprised of farmers and craft workers, laborers and herders, children and the elderly. Few have documents to process or CDs to record. And yet, some do. It's not there's no need - it's just widely distributed. In many ways, the folks that are accessing PCs in these environments are akin to Eric von Hippel's commonly used notion of "lead users"; they go through extraordinary means to gain access, in many ways modifying their environment to make it happen.

Jose Miguel's story here gives us a window into a living system that is ill suited to accommodate computing. The PC was invented and has developed in a highly refined physical and social environment available - and often limited to - the wealthiest countries and to the wealthiest people around the world. This is certainly not to say that all people adopt technology similarly; and yet, there seem to be certain assumed capabilities required to own and operate a computer - capabilities that are mostly beyond the immediate locus of control in any particular home or business.

In the next section, we offer a brief description of our methods and approach, followed by two design directions referencing the example of Jose Miguel.

\section{A Note on Methods}

As part of the People and Practices Group at Intel Corporation, we use ethnographic techniques, e.g., shadowing, participant observation and nondirective, situated interviews, to gain insight into the lives of people, places and systems of interaction in various places around the world. The content of this essay derives from several years of work specifically to identify potential applications, needs, desires, appropriate technologies and business models relevant to a large corporation for bridging the "digital divide".

Overall, we examined many different sites at various levels of detail. In many ways, the work evolved over the years. As a result of this long term, but less structured sampling, we are not making grand claims. We are offering a more generalized position that considers a breadth of data, derived over time, from multiple sites and in various contexts. From this, we extract more generalized patterns reflecting the intersection of people and places that we hope may be beneficial to ICT adoption and use in places currently without access. Field work contributing to this essay, explicitly and implicitly were collected over a period extending from 1999 through 2002; therefore, at the time these data were collected, newer technologies, such as WiFi wireless connectivity were not available.

\section{Design Direction: Locus of Control}

There are many discussions of "digital divide" that have discussed a wide range of attributes defining the "digital divide", including limited infrastructure and limited access to ICTs (cf., Campbell, 2001) as well as presumed benefits of ICTs, including eradication of hunger, gender empowerment and improved education (cf., Batchelor, et al., 2003). It's unnecessary to write about them again here. However, it's the former rather than the latter to which the business units of multinational corporations (MNCs) often turn their attention and apply their considerable resources - when they do anything at all. The issue can be, perhaps crassly, but certainly honestly, summed up as this general question: "What's preventing people from buying our stuff?” The United Nations, among others, clearly supports the contention that ICTs are beneficial to ICT development; so there must be some barriers preventing adoption and use - barriers that reside not with the ICTs themselves, but with the environment.

Rather than delineate the laundry list of issues yet again, I'd like to consider a few small details of the physical environment from Jose Miguel's perspective to illustrate this point: it's the little things- little 
things that often go unconsidered - that add up making a big difference in the ability to effectively use ICTs (Gurstein, 2003). Providing free satellite connectivity won't matter if these "little things" that are part and parcel of the local environment are unconsidered in ICT design. That is, the digital divide is less about them and more about our (those in the high tech industry) limited understanding and intuition about these potential market places.

Let's consider an almost trivial example: There's an electrical extension cord that brings power from one part of the Jose Miguel's house passing right in front of the door to his room over to the computer. Although not the typical focus of high tech research, this extension cord is illustrative of what is often taken for granted.

In American households, extension cords are a commonplace, extra item held in reserve, just in case it's needed. In the extreme case, it's not all that unlikely for an American to find a used extension cord casually discarded in the trash some family put out on the street for collection. (I found a not insignificant portion of my graduate school furnishings in the trash the gracious townsfolk of Somerville Massachusetts left on the street.) In lieu of searching the rubbish bins, a cord similar Jose Miguel's costs US \$2 in a Goodwill store; new from a bona fide hardware store, they cost about US \$12, which represents $0.028 \%$ of the median annual US household income. For Jose Miguel, that same $\$ 10$ is $1.6 \%$ of his household income. An extension cord is not something he can find on the street and it's not something he can get "on the cheap" - because otherwise everyone would. (Interesting aside: While driving between towns north of San Jose, Costa Rica with a man who has a small photo shop, he suddenly pulled over, got out and picked up a log he saw on the side of the street. I gave him a hand. He apologized, but said that the log would be good as part of the background set in his photo studio: "You don't see good things like this on the road often. People take up the good things fast.”)

However much the extension cord can be considered a scarce resource, it is largely within Jose Miguel's control to get one and not having one is not a significant barrier to adopting computing. In fact, in one family home in Cuenca, the third largest city in Ecuador, the light "switch" was actually two ends of wire the physical connection of which provided a live connection and turned on the kitchen light. The family had been unable or unwilling to install, pay for or cajole the landlord into the installation of an actual switch, and yet, the kitchen, being in a windowless room, required light, and not infrequent electric shocks were a small price to pay. Thus, the local infrastructure is not always a barrier to use; given the ability to control the situation, many people are resourceful and find - often minimally - acceptable means. Of course, these inconveniences certainly sum and provide a less than ideal foundation for adopting and using ICTs. Yet, aspects that can be locally controlled have a better chance of being adopted than aspects that are controlled elsewhere.

For example, a grid source of reliable electricity is somewhat beyond Jose Miguel's sphere of influence; and when it's off, he might do something else other than continue writing his thesis. However, we note that his chickens are not heated with electricity, but with liquid propane. If the electricity goes out, they may die - and that's his livelihood; besides, electricity is more expensive than propane and, additionally, he can control when the lamps are on and off in accordance with temperature requirements rather than availability of electricity.

Most computers are not designed with this feature in mind. In India, among other places, some local businesses have taken matters into their own hands and purchased a universal power supply, which acts as a large, rechargeable battery to power the computer during times of no grid provided electricity. Too bad computers do not accommodate different sources of power - propane, wind, sun, car batteries, etc. Designing computing to accommodate various sources of power, for various periods of time seems not unreasonable in these contexts. However, designing ICTs to accommodate these conditions requires an understanding perhaps exceeding the collective experience of many high tech firms whose employees simply assume full power anywhere, anytime. The divide in this case is less about having grid provided, stable electricity and more about limited awareness and understanding on the part of the manufacturers.

The actual provision of power is one thing, but to use the equipment there's an expectation of constancy. For example, in work we've done in India, information kiosk operators use computing and 
connectivity to provide desired services to rural villagers. However, in many places, power is off for at least 12 hours during the day. Daytime, not surprisingly, is when most people open their shops and conduct business. There's a conflict here. Although, as described above, backup power sources are available and used, they are insufficient to operate throughout the day. The result is that services are limited to what can be deferred until the end of the day when the power comes back on. Actually having the alternate power is representative of the fact that this is a business and can justify the capital expenditure. However, because of the power limitation, growth of the business is constrained to services that meet this rather arbitrary power requirement. For Jose Miguel, no power during the day means he needs to read and write at night, when it's dark; in his unheated room, when it's cold. He could aim one of those heat lamps on himself. But then the chicks might have something to say about that.

The point we are trying to make regarding infrastructure is that these details matter a lot for the adoption of technology for everyday use. Every "little thing" that must be overcome is one more barrier in the way. Having electricity is clearly important. Being able to get electricity to where it needs to be is also important. Having an expectation of when you can use it is important. An American corporation may assume a certain balance between proximal (close to the user) and distal (far from the user) control. Such assumptions, when inappropriate, lead to user difficulties in adapting the technology to local contexts. For the corporation, these difficulties reveal themselves as "surprises" that violate their assumptions. I daresay Jose Miguel's relative difficulty acquiring an extension cord would surprise decision makers in most high tech corporations - and it's just one little thing; the dust falling from the adobe ceiling would be another; that his room is unheated would be another. And so on. The result is a "digital divide".

One way around this is to design technology explicitly to support a variable locus of control such that the technology can adapt to reflect an appropriate balance of proximal and distal control. Perhaps it's possible to design technologies such that when considering the long list of infrastructure issues, the question is to not “what's available” - the full set currently assumed simply won't be available for quite some time. Rather, the question is to consider the range of potential infrastructures and design to support a range of available combinations in a way that's also responsible to the corporation.

Let's approach this issue from the perspective of "digital divide". The phrase suggests digital "haves" and "have-nots". It also suggests that the have-nots are missing out, specifically on economic development. Further, the discourse about the "digital divide" leads one to work to create conditions to turn the have-nots into haves through lists of things they don't have. It's a fine, long-term goal. But it's a long-term goal and it assumes parity at some point. Meanwhile, technologies continue to evolve at an increasingly rapid pace and the digital "haves" continue to extract more and more benefit and advantage, meanwhile driving the two sides of the "divide" further apart.

Perhaps what corporations should do is not go down this garden path, and actually design to accommodate local conditions. From a corporate point of view, the goal should be to accommodate the conditions among the have-nots such that they have what the haves have and, therefore, there are fewer and fewer impediments to buying things the corporation is selling. It's really not that radical a concept. Yet, the whole concept of "digital divide" seems to have mobilized a much grander movement that may be, to offer the cliché, missing the trees for the forest.

We find the utility of the "digital divide" as a construct largely without utility in a corporate context because it absolves corporations from a responsibility to make products that suit the market. Rather, high tech corporations ought to address these potential markets in appropriate ways. In this example, they ought to embrace variability in infrastructures and design accordingly. As one direction, we suggest designing to support a variable balance of proximal and distal locus of control.

But still, just having the technology is without significant meaning (Gurstein, 2003). A second direction we propose here is to design to support local participation: designing technologies such that local the local communities can benefit at least as much as any individual. 


\section{Local of Participation}

As we mentioned, Jose Miguel raises chicks as well as working a small plot of land as an organic farm. To you and me, these endeavors might not seem particularly innovative, but he's making an attempt to apply his newly earned college degree to improving the lot of his community. Pollitos Gigantes and the organic farm are experiments he's running to figure out how his community can benefit. That is, he's locally adapting his knowledge - a resource gained from outside the community - to the local conditions. We'll briefly outline three examples and then discuss them in terms of participation.

Example 1: By keeping the chicks warm, more of them survive. Since he purchases the chicks in bulk - by the flat, there's already loss during transportation. Typically, there's further loss due to local conditions and natural attrition. We know that warmth improves yield. But he's got to provide the warmth economically for his business. We already know that a few dollars can represent a significant portion of household income. He's got to reliably improve yield while increasing his operating costs and he's got to do it in his local context of relatively few dollars, limited outlets for sale, limited means of distribution, etc.

Example 2: Farmland is fairly open in Cañar; animals and people use the fields for their daily needs. Rain is limited for half the year; and the town is at elevations exceeding 10,000 feet. Farmland is also not collocated to their homes. Often, Cañari people have to walk long distances to get to and from their fields, which were allocated to them through agrarian reform, where the main crops are potatoes, corn, peas, and grains such as barley and quinoa, indigenous to the Andes. As an aside, Jose Miguel tells us that there are older people who remember more than 80 different varieties of potatoes, many of which are particularly suited to that altitude and climate. Many varieties of corn also appear to be lost and part of Jose Miguel's endeavor is to find their strains and bring them back. In addition, the community likely eats more rice now, because of the price differential; rice is not locally grown and this is therefore not a local solution. Anyway, Jose Miguel knows that certain farming techniques such as irrigation, appropriate fertilization, attentive maintenance, etc., will result in greater yields. Yet, the situation is the same as with pollitos gigantes: it's unclear how to balance local constraints with the techniques he's learned.

Example 3: We invited Jose Miguel to visit and speak at a conference we held at Intel. Together we managed to secure a visa and he arrived. He spoke about his people and himself; then he wanted to see some farms. James is a local organic subscription farmer we happen to know socially and he invited us to his farm. A subscription farm is one in which households subscribe to receive a share of the produce over the course of the farms production, in this case, year round. James himself uses a PDA to track where in his four acres crops are located and when they've been planted, etc. Of course the few Intel people there were particularly interested in this high-tech/low-tech farming operation. On the other hand, Jose Miguel met one of the farm hands and they went off speaking Spanish. Turns out Jose Miguel was particularly interested in the irrigation system, especially the hoses. For James, it's just a low water-use irrigation hose with openings that can be regulated along its length. For Jose Miguel, he saw immediate utility for his village and of course queried the farmhand about all sorts of practical details regarding its manufacture and use. He knew its local value; none of us did. Even James didn't, and he's a farmer. We also found out that the hose can be purchased in various increments, larger ones costing less; if the village aggregated capital to make the purchase it might be of interest. Getting it there, is another question all together.

It is rather impractical for Jose Miguel to discover innovations by coming to the US to speak at a conference and visit a farm. And yet, it is on farms like James' where innovations such as this hose are used because James, as fringe as he is, is actually part of a market. It's only recently that Prahalad \& Hart (2002) \& Prahalad \& Hammond (2001) have posited that there are profitable markets at the "bottom of the pyramid". Their writing establishes that it is possible for large corporations to market to these people. Our question is somewhat different: how - if at all - can ICTs empower people to interact with and participate in extant markets such they don’t need (to wait) to be marketed to, or preached to, or given to?

One way suggested by our research is to think actively about what it means to participate and to imagine technologies that permit appropriate participation. We focus here on what local participation means. In Cañar and surrounding areas, the Carnival festival in February is the focus of a year's planning. 
One of the scattered indigenous villages per year assumes primary responsibility for the entire festival, including its funding, and derives a variety of benefits from the community in response. The responsibility of playing host for the festival is considered a principle honor in the community. Separately, on Palm Sunday, the villagers gather to parade their patron saints to the town cathedral for blessings. During harvest, farmers gather to assist each other with the work through a process knows as the minga, akin to the "barn-raisings" of Amish fame. Jose Luis, a cousin of Jose Miguel, has a small photography shop near the town center; the shop is also a place for various community groups to meet. It's also a place for a musical group to meet, to which Jose Luis and Jose Miguel belong. By the way, most of the equipment for the band is owned collectively, and not individually.

There is at least one mode of participation that is not individual. Jose Miguel is expressly applying his collegiate skills to his community. He's made a conscious choice to remain in his community for that purpose, when most young men his age are emigrating illegally to the U.S., Spain, and other countries His allegiance is to his people and to that place. Participation is communal. Participation is local and locally oriented. In contrast, the PC and its applications - to a large extent - has evolved to support individual, global participation. If Jose Miguel had invented computing, what might it look like?

First, it might support local wireless communication needs - people talking to each other when they are away from their homes and lands - or people within various of the scattered communities coordinating with each other to secure the rights and also to operate commercially. It might serve as a hub for local communications, which means many wireless peripheral devices. Second, its focus might well be far less on document writing, and far more on audio and video communication/archiving - for example, gathering and storing the knowledge of those 80 potato varieties. Third, almost certainly it would support music composition and performance. Fourth, It might also be a mini-projection facility to project movies (and play music) at festivals and in the evenings. Fifth, it could support multiple electronic mailboxes - one per person to function like a postal office of sorts. Sixth, it might serve as a library for books and other reading materials that can be "checked out" or read there. Seventh, it might support a wide range of remote cameras and sensors to monitor their own lands and territories and protect themselves from encroachment from large corporate interests - or at least get a good price. Finally, if he had his druthers, heat from the machine, would be channeled to warm his room - or, perhaps, his chickens,

This is just one list that I daresay reflects a bit more of his interest in local participation and a good deal less of our interest in them as a market. Unfortunately, this list is made without his cooperation. So while these items seem more relevant, it is our supposition that they remain off the mark, being tainted, as they are, by our own biases. Regardless, many of these issues aren't new to Jose Miguel; but he remains without any voice in technology evolution. Heartening for corporations is that many of these needs are now among the cutting edge in terms of technological development. The better news (for manufacturing corporations) is that these sorts of needs are prevalent to large populations around the globe. More distressing is that corporations are going to have to develop a new sensitivity to listen to and collaborate with the majority of the planet.

All of this is not to say that Jose Miguel wishes to remain isolated in his community. As he demonstrated so naturally at James' farm, there's a lot to be learned from outside his community. These are the sort of things ICTs have supported quite well among those with access and all the additional attributes that enable people to effectively use ICTs. What's far more difficult to support is localizing what's available from 'everywhere' to what's relevant to particular individuals in particular locales. These issues appear heavily influenced by business ecosystems, legal structures, property management and entrepreneurial endeavors; this discussion is reserved for another time.

\section{Summary}

The hope of this paper is to motivate technological innovations to support local contexts. Two suggested directions were proposed to emphasize designing to support locus of control and locus of participation. The bulk of this paper, however, is spent in simply relaying the details of the lived 
experience in sufficient detail to make the case for and the connection to innovative technology concepts and ideas.

It is vital, we believe, to attend to the details and to attempt to enliven the lived experience in such a way that it can be "felt" by engineers who are inventing and designing technologies; and it is increasingly important as employees are further removed from the locales for which they may be designing. The vast majority of engineers, marketers and management in multinational corporations simply do not have an intuitive understanding of these locales. They are far from each other - in physical, social, cultural, symbolic and emotional distance. If there must be a "digital divide", it might make more sense and be far more useful for everyone if we were to redefine the divide as a lack of corporate intuition, understanding and empathy for the majority of the planet, than a characterization of haves and have-nots.

\section{Acknowledgements}

We gratefully acknowledge Judy Blankenship's efforts both in the field with us, and in the editing

certain sections this paper. We also thank Hsain Ilhaine and Joan Vinyets for their comments and conversation concerning earlier drafts.

\section{References}

Campbell, D (2001) “Can the digital divide be contained?” International Labour Review, 140 (2), pp 119141.

Gurstein, M (2003) “Effective Use: A Community Informatics Strategy Beyond the Digital Divide”, First Monday, December 2003. Accessed September 27, 2004 from http://www.firstmonday.dk/issues/issue8_12/gurstein/index.html

Prahalad, C.K. \& Hammond, A. (2001) "What Works: Serving the Poor, Profitably: A Private Sector Strategy for Global Digital Opportunity”. Accessed September 27, 2004 from http://www.digitaldividend.org/pdf/serving_profitably.pdf

Prahalad, C.K., \& Hart, S. L. (2002) “The Fortune at the Bottom of the Pyramid.” Accessed September 27, 2004 from: http://www.digitaldividend.org/pdf/bottompyramid.pdf 